REFERENCES:

[1] AntilgE monoclonal antibody (omalizumab) in refractory and relapsing Eosinohilic granulomatosis with polyangiitis (Churg-Struss). Arthritis Rheum 2016; 68: 2274-82

Disclosure of Interests: None declared

DOI: 10.1136/annrheumdis-2019-eular.5116

\section{FRI0266 ABERRANT PD-1 AND VISTA EXPRESSION ON CD4+ TH-CELLS IN GIANT CELL ARTERITIS}

Rebeca Hid Cadena ${ }^{1}$, Rosanne Reitsema ${ }^{2}$, Wayel Abdulahad ${ }^{1,2}$, Minke G. Huitema ${ }^{2}$, Annemieke Boots ${ }^{2}$, Peter Heeringa ${ }^{1}$, Elisabeth Brouwer ${ }^{2}$, Vasculitis Expertise Center Groningen. ${ }^{1}$ University Medical Center Groningen, Pathology and Medical Biology, Groningen, Netherlands; ${ }^{2}$ University Medical Center Groningen, Rheumatology and Clinical Immunology, Groningen, Netherlands

Background: The immune system controls immune responses by balancing positive and negative immune checkpoint (IC) molecules in cell-cell interactions. These co-stimulatory and co-inhibitory molecules allow complete T-cell activation and T-cell effector functions giving rise to an optimal immune response while preventing autoimmunity (1). Failure of tolerance results in the initiation and propagation of pathogenic T-cell responses leading to the development of autoimmune diseases such as Giant Cell Arteritis (GCA). The latter is a complex illness of multiple pathogenic factors with important contributions of both innate and adaptive immunity in its initiation and perpetuation $(2,3)$. Recently, a loss of inhibitory checkpoints on immune cells has been implicated in the immunopathology of GCA $(4,5)$. The possible contribution of IC pathways to the dysregulation of Th-cells in GCA could aid in our understanding of GCA immunopathology.

Objectives: In this study, we aimed to investigate the expression of different IC molecules and their ligands by circulating monocytes, and functionally distinct populations of CD4+T-cells in peripheral blood samples from GCA-patients in comparison to healthy controls (HCs).

Methods: In a cross-sectional study, fresh blood samples were obtained from 30 GCA-patients with/without immunosuppressive treatment (glucocorticoids) and 18 sex and age-matched HCs. The frequency of the expression of different IC including CD80/86, PD-L1, PDL2 and V-domain Ig suppressor of T-cell activation (VISTA) were determined on total monocytes and subsets (classical, intermediate and non-classical). In parallel, expression of the corresponding receptors CD28, Cytotoxic T-Lymphocyteassociated antigen-4 (CTLA-4), Programmed death- 1 (PD-1), and VISTA were determined on total CD4+ and subsets of Th-cells defined by CD45RA and CD25 expression of GCA-patients and HCs by flow cytometry.

Results: The frequencies of CD80/CD86+ and VISTA+ monocytes were decreased in GCA-patients compared to HCs. Proportions of circulating CD4+ Th-cells in GCA-patients were not different when compared to HCs. The frequencies of CD28 and CTLA-4 expressing CD4+Th-cells did not differ between GCA-patients and HCs. In contrast, proportions of PD1 and VISTA expressing Th-cells were significantly decreased in GCA patients. Memory T-cells showed decreased expression of IC molecules. Interestingly, naïve T-cell populations already demonstrated loss of PD-1 and VISTA.

Conclusion: In GCA, lower frequencies of CD80/CD86+ and VISTA+ circulating monocytes were found. Likewise, decreased proportions of PD-1 +CD4+ and VISTA+CD4+ Th-cells were noted. Decrease of negative IC on the surface of immune cells could add to the persistent activation of CD4+T-cells seen in GCA.

\section{REFERENCES:}

[1] Ceeraz S, Nowak EC, Noelle RJ. B7 family checkpoint regulators in immune regulation and disease. Trends in Immunology. 2013.

[2] Samson M, Corbera-Bellalta M, Audia S, Planas-Rigol E, Martin L, Cid $M C$, et al. Recent advances in our understanding of giant cell arteritis pathogenesis. Autoimmun Rev [Internet]. 2017 Aug;16(8):833-44.

[3] Weyand CM, Goronzy JJ. Immune mechanisms in medium and large-vessel vasculitis. Nat Rev Rheumatol. 2013:9(12):731-40.

[4] Watanabe R, Zhang H, Berry G, Goronzy JJ, Weyand CM. Immune checkpoint dysfunction in large and medium vessel vasculitis. Am J Physiol Hear Circ Physiol [Internet]. 2017 May 1;312(5):H1052-9.

[5] Zhang H, Watanabe R, Berry GJ, Vaglio A, Liao YJ, Warrington KJ, et al. Immunoinhibitory checkpoint deficiency in medium and large vessel vasculitis. Proc Natl Acad Sci \{United States of America\} [Internet]. 2017;201616848.
Acknowledgement: Special thanks to the Vasculitis Expertise Center Groningen

Disclosure of Interests: Rebeca Hid Cadena: None declared, Rosanne Reitsema: None declared, Wayel Abdulahad: None declared, Minke G. Huitema: None declared, Annemieke Boots Grant/research support from: grant from MSD in 2010-2015, Consultant for: I was a consultant for Grunenthal Germany 2016-2017, Employee of: I was an employee of Organon, Shering-Plough and MSD from 1991-2011, Peter Heeringa: None declared, Elisabeth Brouwer Speakers bureau: Dr. Brouwer as an employee of the UMCG received speaker fees and consulting fees from Roche which were paid to the UMCG DOI: 10.1136/annrheumdis-2019-eular.5507

\section{FRI0267 DIAGNOSING POLYMYALGIA RHEUMATICA: THE IMPACT OF FAST-TRACK CLINIC AT HOSPITALIZATION RATES}

Stavros Chrysidis ${ }^{1}$, Nikoletta Giannoutsou ${ }^{1}$, Philip Lage-Hansen ${ }^{1}$, Andreas Diamandopoulos ${ }^{2} .{ }^{1}$ South-west Joutland Hospital, Esbjerg, Esbjerg, Denmark; ${ }^{2}$ Martina Hansens Hospital, Oslo, Oslo, Norway

Background: Polymyalgia Rheumatica (PMR) is a common inflammatory autoimmune rheumatic disease, with the highest incidence rates seen in Scandinavia.

One of the challenges in the diagnosis of PMR is the lack of diagnostic tests specific for the disease. The diagnosis may require exclusion of other conditions that can present with polymyalgia symptoms and may lead to hospitalization. Only limited data on hospitalization rates among patients with PMR exists (1).

Ultrasound (US) may be useful in differentiating PMR from non-inflammatory conditions and can also be used for the diagnosis of concomitant Giant Cell Arteritis (GCA)

GCA Fast Track Clinics (FT) using US as the main diagnostic tool have shown both improvement in patient outcomes and decrease in the cost of care(2)

Objectives: To investigate the admission rates of patients diagnosed with PMR and the impact of the FT on these rates.

Methods: A FT clinic for patients suspected to have PMR was established at rheumatological outpatient clinic of South-West Jutland Hospital (serving 250.000inhabitants) in January 2018. Collaboration with the Emergency Medical department was established and patients with PMR symptoms referred to the hospital were examined at FT within 0-1 days, thereby avoiding hospitalization. Similarly, patients referred with PMR symptoms to the outpatient clinic by a GP, were examined at FT within 1-2 days. At FT a thorough history and clinical examination were performed including musculoskeletal and vascular US. Retrospectively data from patients diagnosed with PMR from 2013-2018 was analyzed.

Results: In a 6 years' period, 336 patients were diagnosed with PMR. 54 patients were diagnosed during hospitalization. Hospitalized patients were older (mean values \pm standart deviaton-sd) $73,61 \pm 8,96$ vs 70,94 $\pm 7,97$ years, $p=0,024$, with significantly higher initial C-reactive protein (CRP, mg/l) levels $99 \pm 58,8$ vs $43,9 \pm 37, \mathrm{p}<0,0001$ and a shorter duration of symptoms $(6,92 \pm 5,5$ vs $13,6 \pm 13,7$ weeks, $p=0,0018)$. No differences were found regarding gender, PMR related symptoms, initial prednisolone dose and response to treatment. An equal annual distribution of the number of new diagnosed cases and hospitalizations rates during the first 5 years was found. After the implementation of the FT at January 2018 a significant decrease in hospitalization rates $(19,4 \%$ vs $3,5 \% \quad p=0,001)$ and inpatient days of care $(4,15 \pm 3,1$ vs $1 \pm 0, p<0,0001)$ was observed. The time from symptoms debut to diagnosis was also significantly decreased from 13,74 to 6,79 weeks (Table)

\begin{tabular}{|c|c|c|c|}
\hline & $\begin{array}{c}\text { Diagnosed at } \\
2013-2017 \\
\text { N } 268\end{array}$ & $\begin{array}{c}\text { Diagnosed at } \\
2018 \\
\text { N } 56\end{array}$ & $P$ values \\
\hline Age (years) mean \pm sd & $71,3 \pm 8,5$ & $71,79 \pm 6,6$ & n. s $^{*}$ \\
\hline Gender (female) & $58,2 \%$ & $48,2 \%$ & n.s \\
\hline Duration of symptoms (weeks) mean \pm sd & $13,74 \pm 13,74$ & $6,79 \pm 4,72$ & 0,001 \\
\hline Bilateral shoulder pain & $95,9 \%$ & $98,2 \%$ & n.s \\
\hline Abnormal CRP and/or SR at debut & $91,8 \%$ & $100 \%$ & 0,03 \\
\hline $\mathrm{CRP}(\mathrm{mg} / \mathrm{lt})$ mean $\pm \mathrm{sd}$ & $52,82 \pm 48,3$ & $56,5 \pm 37,2$ & n.s \\
\hline Morning stiffness & $90,3 \%$ & $92,7 \%$ & n.s \\
\hline Hip pain or limited range of motion & $71,4 \%$ & $61,8 \%$ & n.s \\
\hline $\mathrm{RF}$ and aCCP negative & $95,1 \%$ & $100 \%$ & n.s \\
\hline Absence of other joint involvement & $72 \%$ & $75 \%$ & n.s \\
\hline Initial prednisolone dose $(\mathrm{mg})$ mean $\pm \mathrm{sd}$ & $18,44 \pm 8,41$ & $19,2 \pm 9,25$ & n.s \\
\hline Hospitalized n(\%) & $52(19,4 \%)$ & $2(3,5 \%)$ & 0.01 \\
\hline Inpatient days of care mean \pm sd & $4,15 \pm 3,1$ & $1 \pm 0$ & 0,0001 \\
\hline
\end{tabular}

${ }^{*}$ n.s=non-significant 
Conclusion: The annual hospitalization rates in connection with PMR diagnosis at South-west Denmark during a 5 year period were estimated to be $19,2 \%$. The implementation of a FT ultrasound clinic decreased significantly the hospitalization rates among patients with PMR. REFERENCES:

[1] Gran JT,Myklebust G. The incidence of PMR and temporal arteritis in the county of Aust Agder, South Norway: a prospective study 1987-94. J Rheumatol 1997.

[2] Diamantopoulos AP et.al. The fast-track ultrasound clinic for early diagnosis of GCA significantly reduces permanent visual impairment: towards a more effective strategy to improve clinical outcome in giant cell arteritis? Rheumatology (Oxford) 55:66-70

Disclosure of Interests: None declared

DOI: 10.1136/annrheumdis-2019-eular.3494

\section{FRI0268 CLINICAL FEATURES OF TAKAYASU'S ARTERITIS FROM AN INCEPTION COHORT: EARLY DISEASE IS CHARACTERIZED BY 'SYSTEMIC INFLAMMATION'}

Fatma Alibaz-Oner, On behalf of Turkish Takayasu Arteritis Study Group. Marmara University Faculty of Medicine, Internal Medicine, Division of Rheumatology, Istanbul, Turkey

Background: There is only retrospective and very limited data for the long term prognosis of Takayasu's Arteritis (TAK), a rare large-vessel vasculitis.

Objectives: In this study, we aimed to present the preliminary results of a Takayasu Inception Cohort settled for long term, prospective follow-up of only newly-diagnosed patients with TAK.

Methods: Patients fullfilling the American College of Rheumatology 1990 criteria for TAK and diagnosed in the last 12 months were included to the study. Patients' data were recorded in an electronic database of an international "Takayasu's Arteritis Registry" requiring baseline and at least annual visits. Data is compared with an historical Turkish cohort previously published (Bıçakçıgil, et al, 2009).

Results: The study included 170 patients (age: $38.5 \pm 13.1$ years, F/M: 143/27) with TAK from 15 tertiary Rheumatology centers in Turkey. The mean symptom duration of patients was 5.2 years at diagnosis. According to the angiographic classification, $68.2 \%$ of the study group had type I and only $18.3 \%$ had type $V$ disease. When we compared our results to our retrospective cohort (previously published by Turkish Takayasu Arteritis Study Group), constitutional symptoms $(115 / 165=69.6 \%$ vs $66 \%$ ) and limb claudication $(87 / 131=66.4 \%$ vs $48 \%)$ were observed to be more frequent, whereas pulselessness $(45 / 130=34.6 \%$ vs $88 \%)$ was less in the inception cohort.(Table 1) Carotidynia was present only in the inception cohort. Similarly, mucocutaneous symptoms also seem to be a feature of newly-diagnosed disease $(30 / 162=18.5 \%$ vs $8.8 \%)$.

Regarding comorbidities at diagnosis, the rate of dyslipidemia was 17.6 $(30 / 165) \%$, diabetes mellitus $15.1(25 / 165) \%$, smoking $20(34 / 164) \%$ and obesity (BMl>30) $14(22 / 157) \%$ among TAK patients. All patients were given oral corticosteroid (CS) therapy $(0.5-1 \mathrm{mg} / \mathrm{kg})$ at diagnosis, 17 patients $(17 / 170=10 \%)$ also having CS pulses. In addition to CSs, 86 patients $(50.6 \%)$ were given methotrexate, 31patients $(18.2 \%)$ azathioprine, $6(3.5 \%)$ cyclophosphomide, 12 patients (7.1\%)leflunamide, 2(1.2\%) patients mycophenolate mofetil and $5(2.9 \%)$ patients biologics at diseaseonset(2 tocilizumab, 2 infliximab, 1 adalimumab). Biologic agents were chosen for 7 patients $(7 / 32)$ at last vizit(1 adalimumab, 4 tosiluzumab, 2 infliximab).

Seventy-three patients (42.9\%) had follow-up > 3 months. Remission was observed $78 \%$ of patients. At least one relaps was observed $40 \%$ of these patients. Mortality rate was $4.1 \%$ (3/73 patients) during a mean 25.7 months follow-up.

Conclusion: Our results suggest that, in an inception cohort, signs and symptoms of 'systemic inflammation' is more prominent in newly-diagnosed TAK patients, whereas vascular extent and damage accumulates during the disease course. The long term follow-up of our inception cohort shows that $40 \%$ of patients relapse within 2 years after diagnosis in spite of IS treatments.

\section{REFERENCES:}

[1] Bicakcigil M, Aksu K, Kamali S, et al. (2009) Takayasu's arteritis in Turkey - clinical and angiographic features of 248 patients. Clin Exp Rheumatol. 27, 59-64.
Table 1. Clinical characteristics of Inception and Retrospective Cohorts from Turkey

\begin{tabular}{lcc}
\hline & $\begin{array}{c}\text { Inception Cohort } \\
(\mathrm{n}=170)\end{array}$ & $\begin{array}{c}\text { Retrospective Cohort } \\
(\text { Bıçakçıil, et al) } \\
(\mathrm{n}=248)\end{array}$ \\
\hline Constitutional symptoms & $115 / 165(69.6 \%)$ & $163 / 248 /(66 \%)$ \\
Limb claudication & $87 / 131(66.4 \%)$ & $119 / 248(48 \%)$ \\
Carotidynia & $31 / 130(18.2 \%)$ & - \\
Pulseless & $45 / 130(34.6 \%)$ & $218 / 248(88 \%)$ \\
Musculoskeletal manifestations & $90 / 163(52.9 \%)$ & $104 / 248(42 \%)$ \\
Mucocutaneous manifestations & $30 / 162(17.6 \%)$ & $22 / 248(8.8 \%)$ \\
Respiratory manifestations & $47 / 163(28.8 \%)$ & $22 / 184(12 \%)$ \\
Neurologic manifestations & $69 / 163(40.6 \%)$ & $156 / 248(63 \%)$ \\
Cardiac involvement & $64 / 146(43.8 \%)$ & $141 / 248(57 \%)$ \\
Ophthalmologic involvement & $27 / 166(16.2 \%)$ & $57 / 248(36 \%)$ \\
& &
\end{tabular}

Disclosure of Interests: None declared

DOI: 10.1136/annrheumdis-2019-eular.7258

\section{FRI0269 COMPARATIVE STUDY OF INFLIXIMAB VERSUS ADALIMUMAB IN REFRACTORY UVEITIS DUE TO BEHÇET'S DISEASE. NATIONAL MULTICENTER STUDY OF 177 CASES}

Belén Atienza-Mateo, José Luis Martín-Varillas, Vanesa Calvo-Río,

Rosalía Demetrio-Pablo, Emma Beltrán, Juan Sánchez-Bursón, Marina Mesquida, Alfredo Adan, Victoria Hernandez, Marisa Hernández-Garfella, Elia Valls-Pascual, Lucía Martinez-Costa, Agusti Sellas-Fernández, Miguel Cordero-Coma, Manuel Díaz-Llopis, Roberto Gallego, José L. García-Serrano, Norberto Ortego, Jose M. Herreras, Alejandro Fonollosa, Ángel García-Aparicio, Olga Maiz-Alonso, Ana Blanco, Ignacio Torre-Salaberri, Cruz Fernandez-Espartero, Vega Jovani, Diana Peiteado, Esperanza Pato, Juan Cruz, Carlos Férnandez-Cid,

Elena Aurrecoechea, Miriam García-Arias, Santos Castañeda, Miguel A. CaracuelRuiz, Carlos A. Montilla-Morales, Antonio Atanes-Sandoval, Félix Francisco, Santos Insua, Senen González-Suárez, Amalia Sanchez-Andrade,

Fernando Gamero, F. Luis. Linares Ferrando, Fredeswinda Romero, A. Javier García-González, Raquel Almodovar, Enrique Minguez, Carmen Carrasco-Cubero Alejandro Olive, Julio Vázquez, Oscar Ruiz-Moreno, Fernando Jiménez-Zorzo, Javier Manero, Santiago Muñoz Fernandez, Cristina Fernández-Carballido, Esteban Rubio-Romero, Fred Antón Pages, J. Francisco. Toyos Sáenz de Miera, Myriam Gandia Martinez, David Díaz Valle, Francisco J. López-Longo, Joan Miquel Nolla, Enrique Raya, Marcelino Revenga, J. Luis Hernández,

Monica Calderón-Goercke, D. Prieto-Peña, Iñigo González-Mazón, Lara

Sánchez Bilbao, Miguel Á. González-Gay, Ricardo Blanco. Reference hospitals,

Rheumatology, Ophthalmology and Internal Medicine Units, Spain

Background: Uveitis is one of the major causes of disability of Behçet's disease (BD). According to the "Expert panel recommendations", anti-TNF therapy with infliximab (IFX) or adalimumab (ADA) may be considered as first- or second-line therapy for patients with BD-ophthalmic manifestations.

Objectives: To compare IFX versus ADA as first biologic drug in refractory uveitis due to BD for 1-year period.

Methods: Multicenter study of BD-associated uveitis refractory to conventional non-biologic treatment. Dosing schedule: IFX $3-5 \mathrm{mg} / \mathrm{kg}$ iv at 0,2 and 6 weeks and then every 4-8 week, and ADA $40 \mathrm{mg} / \mathrm{sc} /$ every other week without loading dose. Main comparative outcome measures: safety and efficacy, assessing the intraocular inflammation, macular thickness, visual acuity, degree of immunosuppression load, drug retention, and glucocorticoid-sparing effect.

Results: 177 patients (316 affected eyes) were included. IFX was used in 103 and ADA in 74. No significant differences at baseline were observed regarding main demographic features, previous therapy and ocular severity. After 1 year of therapy, we observed an improvement in all ocular parameters in IFX vs ADA groups: AC inflammation $(78.18 \%$ vs $92.31 \%)$, vitritis $(78.95 \%$ vs $93.33 \%)$, retinal vasculitis $(97 \%$ vs $95 \%)$, macular thickness $(264.89 \pm 59.74$ vs $250.62 \pm 36.85)$, and BCVA $(0.67 \pm 0.34$ vs $0.81 \pm 0.26)$. Drug withdrawal was observed in $57(55.33 \%)$ of IFX group and in $21(28.37 \%)$ of ADA group.

Conclusion: After 1 year of therapy in refractory BD-associated uveitis, ADA showed a statistically better outcome than IFX in improvement of BCVA, vitritis and drug retention.

\section{REFERENCES}

[1] Levy-Clarke G, et al. Expert panel recommendations for the use of antitumor necrosis factor biologic agents in patients with ocular inflammatory disorders. Ophthalmology. 2014; 121:785-96. 